\title{
A Comunicação nas ciências interdisciplinares: o compromisso de um discurso - o caso da área da Saúde
}

\author{
Anabela Félix Mateus \\ LabCom.IFP/Universidade da Beira Interior \& FCT \\ E-mail: anabela.mateus@netcabo.pt
}

\begin{abstract}
Resumo
A complexidade dos problemas modernos da sociedade e uma necessidade de inovação levam a considerar um processo de convergência entre diferentes áreas de investigação científica. Os desafios do tempo globalizado têm na interdisciplinaridade um de seus pilares. Algo é de salientar: distintas ciências, discursos próprios. O efeito sinérgico que resulta de uma complementaridade ativa das diversas ciências que se propõem a um mesmo objetivo só se obtém através da ação da comunicação, presente ao longo todo o processo. A área da saúde revela-se particularmente importante: apresenta um discurso particular, muitas vezes técnico, e tendo como referências absolutas as

onais, demonstrando-se praticamente fechado aos usuários que a ele recorrem. No presente artigo analisamos a eficácia da comunicação verbal utilizada na área da Saúde, voltada para seu público mais direto. Usamos análise do discurso de entrevistas informais diretas a responsáveis pela comunicação verbal na relação médico / paciente e análise de conteúdo de bulas de medicamentos, realizada por consumidores comuns. Esperamos contribuir para incentivar a reflexão consciente pelos atores envolvidos na codificação e transmissão de mensagens, a fim de se obter uma maior eficácia da comunicação num relacionamento de transparência em Saúde.
\end{abstract} simbologias e terminologias dos profissi-

Palavras-chave: Comunicação; informação; saúde; interdisciplinaridade.

\begin{abstract}
The complexity of the modern problems of the society and the necessity of innovation imply significantly a convergence process between different areas of

scientific research. The challenges of globalization have on interdisciplinarity one of its pillars. Something has to be highlighted: different sciences, dif-
\end{abstract}


ferent speeches. The synergistic effect, which results from an active complementarity of different sciences that have the same goal, can only be obtained through the communication action, present all throughout the process. The health area is especially important: it presents a particular discourse, often technical, and with absolute references the symbolics and the terminology of professionals, being virtually closed to users who recourse to it. In this article we analyze the effectiveness of verbal communication used in the health area, directed most closely to the public. We use discourse analysis of direct informal interviews by the person responsible for medical verbal communication / patient relationship and content analysis of inserts labeling drugs, done by ordinary consumers. We hope to contribute and encourage the conscious reflection by the actors involved in encoding and in the transmission of messages in order to obtain a greater effectiveness of communication and a relationship of transparency in Health.

Keywords: Communication; information; health; interdisciplinarity.

\section{A Comunicação nas Ciências da Saúde}

TNFORMAÇÃO e comunicação encontram-se na base de uma sociedade que se pretende saudável. Passa pela pesquisa; passa, como consequência, pela divulgação de novos saberes.

A questão da informação é levantada pela necessidade da existência de códigos comuns de quem informa e de quem necessita de ser informado:

A necessidade de estabelecer uma ancoragem entre a comunicação e a saúde vem merecendo a dedicação de profissionais destas duas áreas, principalmente desde que, a partir da segunda metade do século XX, um novo paradigma propôs um deslocamento da doença para a saúde, visando sua promoção e prevenção, com a utilização de diversas ações comunicativas como ferramenta indispensável para atingir este objetivo (Bertol, p. 258)

Por outro lado, a complexidade dos problemas da sociedade moderna e a necessidade de inovação, levam a considerar um processo de convergência entre as diversas áreas de pesquisa científica.

Os desafios do tempo globalizado assentam hoje na inevitável interdisciplinaridade. Interdisciplinaridade que, por sua vez, sem o fator dinâmico 
A Comunicação nas ciências interdisciplinares: o compromisso de um discurso - o caso da área da Saúde

da Comunicação e a fundamental responsabilidade da interligação entre os distintos campos da ciência que lhe estão inerentes, não é passível de se concretizar.

Mas algo há a realçar: ciências distintas, discursos próprios. A necessidade de um esforço suplementar de cada uma das áreas, complementares, em ordem a uma comunicação eficaz e eficiente, impõem-se dentro de cada grupo, devido às características dos seus discursos técnicos e científicos, particulares a cada uma, na maior parte das vezes também difíceis de descodificar aos públicos a quem se dirigem. "Veja-se o exemplo da saúde pública, em que se tem de trabalhar com meio-ambiente, saúde, economia, participação social, comunicação, envolvimento da sociedade, epidemiologia, estatística, entre outras"(Professor Philippi Jr.) ${ }^{1}$. Tudo em simultâneo.

É nosso objetivo alertar para uma realidade não muito contemplada pelas Ciências da Saúde em Portugal, detentoras de linguagens e discursos muito próprios, herméticos e virados para si próprios, caraterizados por um particular tecnicismo, colocando num segundo plano de importância, muitas das vezes, os principais recetores das mensagens transmitidas: o público em geral.

Não duvidamos também que é do intercâmbio e da partilha de áreas distintas que se conseguem sinergias que levam a novos saberes. E como é de relembrar, o efeito sinérgico que resulta da complementaridade ativa das várias ciências que se propõem a um mesmo objetivo, só se obtém através da ação da Comunicação.

Há pois que estar atento, à grande necessidade cada vez mais presente ao longo de todo o processo no sentido de um esforço a ser feito pelos técnicos e especialistas, nomeadamente na tentativa de Informação ao grande público, os utentes, dos mais afetados com falta de informação pelo tecnicismo da linguagem registada e hermetismo dos discursos apresentados, e também em relação aos parceiros de distintas áreas, numa necessidade de partilha de informação e intercâmbio, também cada um com linguagens e discursos próprios, o que se traduz em barreiras muitas vezes difíceis de transpor.

1. "Ciência caminha para a interdisciplinaridade, dizem pesquisadores" $3^{\mathrm{a}}$ Reunião de Coordenadores de Programas de Pós-Graduação da Área Interdisciplinar (Recopi) Finatec, Brasília, 2008, on line. 


\title{
A pertinência dos conceitos e sua aplicação
}

\section{Interdisciplinaridade e sua oportunidade hoje}

O termo foi publicado pela primeira vez em 1937 pelo sociólogo Louis Wirtz que definia a interdisciplinaridade como a qualidade daquilo que é interdisciplinar, e a entendia por aquilo que se realiza com a cooperação de várias disciplinas.

O facto é que passado bem mais de um quarto de século o termo mantémse fiel a esse conceito: para que haja interdisciplinaridade é preciso que haja mais de uma disciplina e implica uma relação de troca entre elas de modo a cumprirem objetivos e obterem mais-valias que de uma forma isolada não conseguiriam alcançar.

Segundo Japiassu (1976, p.74, in Francischet):

\begin{abstract}
A interdisciplinaridade caracteriza-se pela intensidade das trocas entre os especialistas e pelo grau de interação real das disciplinas no interior de um mesmo projeto de pesquisa (e traduz-se como) (...) um método de pesquisa e de ensino suscetível de fazer com que duas ou mais disciplinas interajam entre si, esta interação podendo ir da simples comunicação das idéias até a integração mútua dos conceitos, da epistemologia, da terminologia, da metodologia, dos procedimentos, dos dados e da organização da pesquisa. (Japiassu, 1991, p.133, in Sommerman: 2006, p.30, cit por Staudt op. cit, p.17).
\end{abstract}

A importância da interdisciplinaridade assenta e deriva do desenvolvimento científico-técnico pelo que veio proporcionar o surgimento de numerosos ramos científicos. Nessa medida permite não só integrar novas abordagens na busca de um conhecimento cada vez mais aprofundado, como possibilita que o objeto de estudo seja abordado de uma forma integral e sob múltiplos enfoques metodológicos.

Assim pode ser encarada como uma abordagem metodológica que consiste na procura sistemática da integração das teorias, dos instrumentos e das fórmulas de ação científica de diferentes disciplinas, baseada numa conceção multidimensional dos fenómenos. É por isso que hoje em dia a tendência é geral, e independentemente da forma, todas as ciências recorrem à interdisciplinaridade para atuarem e se desenvolverem. 
A Comunicação nas ciências interdisciplinares: o compromisso de um discurso - o caso da área da Saúde

\section{Comunicação}

Precisamos saber do que falamos. Precisamos entender-nos.

Comunicar é isso. Utilizar um código que seja comum a todos os intervenientes de um mesmo grupo.

As perspetivas são muitas: desde a Sociologia, à Antropologia, passando pela Psicologia, ciências que se tangem, também com o ser humano enquanto interveniente direto e fundamental ao processo. Trata-se de importantes e significativos exemplos, mas tão só; noutra perspetiva, um campo habitualmente não muito referenciado ao tratar-se das Ciências da Comunicação: com objetos e meios distintos, mas objetivos idênticos, encontram-se as tecnologias traduzidas no meio da informática e afins; fundamental referir, a etimologia do termo Comunicação, Comunicar. A sua origem encontra-se no Latim 'communis', pôr em 'comum'.

Uma nota ainda, perante o teor do presente trabalho: a inegável relação implícita entre a Linguística e a Teoria da Comunicação: já Aristóteles defendia, que o homem é um ser social, e a linguística é-lhe fundamental....

Na sequência de tudo o que foi dito, ninguém poderia afirmar melhor do que Marques de Melo: “(...) ao analisar o fenômeno comunicativo, cada ciência e corrente filosófica utiliza a sua própria perspectiva, a sua própria terminologia, os seus conceitos específicos. (1975 p.14)".

\section{Informação}

Existem muitas e variadas definições de informação, bastante complexas.

Muito simplesmente pode-se dizer que a informação é um conjunto organizado de dados que constitui uma mensagem sobre um fenómeno ou evento com vista a permitir resolver problemas e tomar decisões, tendo em conta que o seu uso racional é a base do conhecimento; noutra perspetiva a informação apresenta-se como um fenómeno que confere significado ou sentido às coisas, uma vez que através de códigos e de conjuntos de dados, forma os modelos do pensamento humano.

Em termos muito sintéticos Zorrinho (1995) definiu-a como "um instrumento de compreensão do mundo e da acção sobre ele". 


\section{Comunicação em saúde}

Comunicação em saúde, uma área específica da Comunicação, diz respeito ao estudo e utilização de estratégias de comunicação para informar e para influenciar as decisões dos indivíduos e das comunidades no sentido de promoverem a sua saúde.

Esta a é uma definição, que vai de encontro às nossas convicções na linha do que propõe Teixeira (p. 615. s/d).

\section{Os Métodos de Trabalho}

Para a realização do presente trabalho recorreu-se a uma análise de teor puramente qualitativo, a Análise do Discurso, indiferentemente aplicada a entrevistas orais e documentos originalmente escritos, nomeadamente as bulas dos medicamentos.

Segundo Caregnato; Mutt (2006, p.681) com a Análise do Discurso, a língua é considerada opaca e heterogênea, logo torna-a passível de equívocos, falhas, bloqueios de comunicação. O sentido da palavra, do discurso, não é objetivo mas subjetivo. Inclusivamente pelas posições distintas de conhecimento entre emissor e recetor - especialista e utente.

Para Pêcheux, (in Caregnato; Mutti, idem, ibidem) "todo dizer é ideologicamente marcado". No presente contexto a linguagem utilizada pelos especialistas da área da medicina e, particularmente grande parte das bulas que acompanham os medicamentos e pretendem informar sobre o produto em causa, encontrar-se-ão particularmente marcadas pelo tecnicismo que acompanha a área da saúde. Uma linguagem hermética e adaptada ao coletivo de um campo científico, representante de uma classe de investigadores e especialistas.

Na generalidade, os cientistas não são eficientes ou eficazes na explanação do seu trabalho para uma vasta audiência, sobretudo porque se encontram centrados e focados na própria pesquisa, e não estão particularmente bem acostumados a comunicar esse conhecimento ao público em geral. Eles tendem a usar palavreado, desnecessariamente detalhado ou demasiado técnico. Caiem em jargão incompreensível para qualquer um que esteja fora do seu campo de investigação (Hartz; Chappel in Mateus:2010, p.13) 
A Comunicação nas ciências interdisciplinares: o compromisso de um discurso - o caso da área da Saúde

Se embora, por uma questão de isenção científica na maior parte das investigações se decida por um afastamento entre o conhecimento empírico dos autores e a investigação realizada, as experiências vividas pela autora no presente campo é de tal forma rica, que se demonstra impossível não a incluir na presente análise.

É de recordar que este tipo de análise não implica uma análise exaustiva do documento escrito ou entrevista em causa. Qualquer elemento aí existente pode ser estudado enquanto marca linguística, ou "marca de discurso", podendo ser selecionadas poucas marcas linguísticas para interpretação. Tratase de uma análise vertical e não horizontal. O importante é captar a marca linguística e relacioná-la com o contexto sócio-histórico. (Caregnato; Mutti, op. cit.).

O que se pretende é, através das reações diretas dos usuários e utentes, no fundo do público em geral, verificar da eficácia do discurso técnico habitualmente utilizado.

\section{Discussão}

\section{Introdução}

A apresentação de alguns casos caraterísticos de entre as várias situações encontradas irá permitir uma análise simples da realidade mais vasta que estudámos e que se pretende deixar registada.

Com o presente trabalho pretendemos, em particular, um alerta para a necessidade da comunicação eficaz e eficiente, também para o campo da Saúde, pelo que não temos como objetivo traduzir o discurso particularmente técnico, muitas vezes inacessível aqui apresentado.

Ressalvamos, no entanto, algumas situações em que encontrámos um esforço por parte dos responsáveis dos textos informativos dos medicamentos em alcançarem o público em geral, ao apresentarem uma explicação suplementar simplificada com linguagem acessível do dia-a-dia complementando o texto técnico do folheto informativo. Far-lhe-emos justiça, demonstrando uma situação no ponto segundo com o Medicamento D. 


\section{Análise de casos no âmbito das entrevistas}

- Perante um pedido de esclarecimento a um especialista sobre do que se tratava a esclerose múltipla, obteve-se a seguinte resposta:

"A esclerose múltipla é uma doença inflamatória, que afeta a capa de mielina responsável pela condução nervosa, reconhecida como a substância branca do sistema nervoso."

- Também na tentativa de se entender as causas do hipotiroidismo e como melhor lidar com as doenças da tiroide, o resultado foi o seguinte:

"O hipotiroidismo é uma afecção em que a glândula tiróide tem um funcionamento anómalo e produz muito pouca quantidade de hormona tiróidea. O hipotiroidismo muito grave denomina-se mixedema. (...)

No hipotiroidismo é usada a levotiroxina (...).No hipertiroidismo, também é possível fazer tratamento farmacológico, com o metimazol, (...) Quando estamos perante um bócio nodular tóxico, o tratamento pode ser com iodo radioactivo ou cirúrgico - No caso da Doença de Graves, regra geral, o tratamento é farmacológico (...). poderemos ter de optar pela cirurgia ou pelo tratamento com iodo radioactivo."

- Uma situação distinta, digna de referência, é a de um anúncio informativo a que tivemos acesso através de uma especialista do campo da saúde, que abaixo relatamos na íntegra:

"Quelatos de gadolínio" 2

"O primeiro contraste paramagnético foi aprovado para uso clínico em 1988. O gadolínio $(\mathrm{Gd}+3)$ é um íon metálico paramagnético que reduz o tempo de relaxamento de T1 e T2. Devido à toxicidade de sua forma iônica, ele é usado como um quelato, ou seja, moléculas orgânicas grandes (complexo ligante) formam um complexo estável ao seu redor. O quelato reduz a chance de toxicidade. A freqüência de reações adversas é baixa. Os meios de

2. Por gentiliza da Prof. Dra. Ana Lúcia de Alcantara Oshiro. 
A Comunicação nas ciências interdisciplinares: o compromisso de um discurso - o caso da área da Saúde

contraste paramagnéticos são largamente utilizados e eram considerados seguros, mesmo em pacientes com função renal comprometida. Estes contrastes são rapidamente eliminados em pacientes com função renal normal, entretanto, em pacientes com insuficiência renal a meia-vida é prolongada (34-53 horas). Possíveis efeitos colaterais podem ocorrer devido à meia-vida prolongada ou pela liberação de gadolínio livre (forma iônica $\mathrm{Gd}+3$ ).

Relatos recentes têm demonstrado forte correlação entre o desenvolvimento da FSN e a exposição aos quelatos de gadolínio utilizados em exames de ressonância magnética, especialmente o gadodiamide. Um estudo recente detectou a presença de gadolínio na pele e nos tecidos moles de pacientes com a doença.

Thomas Grobner foi o primeiro a propor esta relação. Ele relata que cinco dos nove pacientes expostos ao gadodiamide, desenvolveram a doença em 2-4 semanas. Descreve ainda que a acidose pode ser um co-fator essencial na patogênese da doença".

In "Fibrose Sistêmica Nefrogênica: possível relação com contrastes à base de gadolínio"

Dr. Sandro Fenelon

\section{Análise de Bulas de medicamentos}

Não é demais recordar que a bula tem a função de informar o modo de tomar o medicamento, assim como de precatar qualquer efeito secundário, advertindo para as interações e efeitos secundários do mesmo. Dirige-se a todos os elementos da sociedade, independentemente do seu grau de escolaridade e integração na sociedade.

Limitar-nos-emos a destacar algumas poucas indicações apresentadas em folhetos de medicamentos obtidos praticamente de forma aleatória.

"Medicamento A

Efeitos Secundários

- (...) Hepatotoxicidade com doses altas (...)

- (...) alterações sanguíneas (trombocitopenia, pancitopenia, neutropenia, agranulocitose e anemia hemolítica 
Interacções Medicamentosas e Outras

- Não se recomenda a administração simultânea de 'Medicamento A' com aspirina, salicicatos (...). O emprego simultâneo de diflunisal com 'Medicamento A' aumenta o risco de hepatotoxicidade. (...). O efeito de 'Medicamento A' é inibido pela administração de colestipol, colestiramina e estrogénios. A isoniazida reforça a capacidade hepatotóxica do Medicamento A"”

"Medicamento B

- Este medicamento contém aspartame. O aspartame é uma fonte de fenilalanina, o que pode ser prejudicial para as pessoas com fenilcetonúria"

"Medicamento C

- Como o perfil antiepiléptico do 'Topiramato' difere acentuadamente do das benzodiazepinas, ele pode modular um subtipo do receptor GABAA insensível à benzodiazepina. O 'Topiramato' antagoniza a capacidade do kainato ativar o subtipo kainato/AMPA (ácido (amino-3- hidroxi-5-metilisoxazol-4-propiônico) do receptor aminoácido excitatório (glutamato), mas não exerce nenhum efeito aparente sobre a atividade do N-metil-D-aspartato (NMDA) no subtipo de receptor NMDA."

"Medicamento D

Indicações terapêuticas (...)

- disminorreia (dores menstruais) (...)

- como analgésico (alívio da dor) ou antipirético ( diminuição da febre) $(. .$.

- (...) ex. luxações - deslocação anormal das extremidades ósseas de uma articulação; (...)

- menorragia ( menstruação anormalmente abundante e que se prolonga para lá da sua duração habitual) Não tome Naproxeno

- Se tem hipersensibilidade (alergia) (...)

- Se alguma vez sofreu de rinite (inflamação aguda ou crónica da mucosa nasal), pólipos (alterações da mucosa nasal) (...)"

Nota: destaques da autora 
A Comunicação nas ciências interdisciplinares: o compromisso de um discurso - o caso da área da Saúde

\section{Conclusões}

Resta-nos umas muito breves considerações em termos de reflexão:

Importa referir que os exemplos aqui apresentados traduzem os resultados generalizados do trabalho efetuado.

Dessa forma:

- Perante o observado verifica-se que estamos perante uma mera informação unidirecional, de elevado pendor técnico, que não cumpre os princípios básicos da comunicação, não tendo em atenção os tipos de público a que se destina.

- Reconhecendo-se na Comunicação, oral e escrita, um papel de primeira linha enquanto elemento que une os distintos elementos da área da saúde, será fundamental que os responsáveis no processo primem para que ela se concretize de forma efetiva e eficiente.

- Atendendo a que os utentes dos serviços médicos e recetores das informações prestadas e cedidas fazem parte de um todo indiferenciado de conhecimentos, cabe aos responsáveis pela informação correspondente à Saúde e à classe médica um esforço para o acompanhamento de todos quanto recorrem ao sistema, independentemente do seu nível de experiências culturais, graus académicos ou especializações técnicas e científicas.

\section{Referências Bibliográficas}

Bertol, S. (s.d.). Comunicação e Sociedade, 41: 258, www.revistas.univerciencia.org.

Caregnato, R.C.A. \& Mutti, R. (2006). Pesquisa qualitativa: análise de discurso versus análise de conteúdo. Texto Contexto Enferm, Out-Dez, 15(4): 679-688. Florianópolis.

Francischett, M.N. (s.d.). O entendimento da interdisciplinaridade no cotidiano. BOCC. www.bocc.ubi.pt.

Hartz, J. \& Chappel, R.W. (1997). Apart: How the Distance Between Science and Journalism Threatens America's Future. First Amendment Center, Nashville.

Japiassu, H. (1976). Interdisciplinaridade e a Patologia do Saber. Rio de Janeiro: Imago. 
Marques de melo, J. (1975). Comunicação Social: teoria e pesquisa. $4^{\mathrm{a}}$. ed. Petrópolis: Vozes.

Mateus, A. (2010, Aug.). Comunicação na saúde - a responsabilidade da física médica. Apontamentos de apoio ao Curso de Física Médica. UFU - Minas Gerais, Brasil

Pêcheux, M. (1993). Análise automática do discurso (AAD-69). In F. Gadet \& T. Hak (Org.). Por uma análise automática do discurso: uma introdução à obra de Michel Pêcheux (pp. 61-105). $2^{\mathrm{a}}$ ed. Campinas (SP): Ed Unicamp.

Perles, J.B. (s.d.). Comunicação: conceitos, fundamentos e história. BOCC. www.bocc.ubi.pt

Sommerman, A. (2006). Inter ou transdisciplinaridade? da fragmentação disciplinar ao novo diálogo entre os saberes. São Paulo: Paulus.

Staudt, D.T. ( 2008). A interdisciplinaridade em atenção básica à saúde. Boletim da Saúde, Jan./Jun., 22(1). Porto Alegre.

Teixeira, J.AC. (1996). Comunicação em saúde - Relação Técnicos de Saúde - Utentes. Notas didácticas. SEAC-Escola de Educação Profissional. Curso Auxiliar de Saúde. www.escolaseac.com

Zorrinho, C. (1995). Gestão da Informação. Condição para Vencer. Iapmei. 